\title{
O PODER JUDICIÁRIO E AS POLÍTICAS DE SANEAMENTO BÁSICO NO ESTADO DO RIO DE JANEIRO
}

\author{
Nicholas Arena Paliologo* \\ Daniel Machado Gomes*
}

Resumo

O objetivo do trabalho é analisar a judicialização das políticas públicas de saneamento básico no estado do Rio de Janeiro e seus respectivos impactos. Para isso, adotou-se a metodologia da revisão bibliográfica para tratar da doutrina da efetividade das normas constitucionais, o agigantamento do Poder Judiciário frente aos outros poderes e a consolidação do saneamento básico como direito fundamental. Em seguida, optou-se pelas as análises qualitativas e quantitativas para analisar as ações ajuizadas. Conclui-se pela necessidade de criação de parâmetros específicos para a atuação judicial, respeitando o plano de metas, recursos orçamentários e as disposições previstas na própria lei federal.

\section{Palavras-chave:}

direitos sociais; judicialização; efetividade; saneamento; políticas públicas

\section{THE JUDICIARY AND BASIC SANITATION POLICIES IN THE STATE OF RIO DE}

\section{JANEIRO}

\section{Abstract:}

This study aims to analyze the judicialization of public policies on sanitation in the state of Rio de Janeiro and their impacts. For this, the methodology of the bibliographic revision was adopted to deal with the doctrine of the effectiveness of the constitutional norms, the enlargement of the Judiciary Power and the consolidation of basic sanitation as a fundamental right. The qualitative and quantitative analyzes were used to analyze the lawsuits. It is concluded that there is a need to create parameters for judicial action, respecting the targets plan, budgetary resources and the provisions set forth in the federal law.

\section{Keywords:}

social rights; judicialization; effectiveness; sanitation; public policies

\footnotetext{
${ }^{*}$ Mestre em Direito e Políticas Públicas pela Universidade Federal do Estado do Rio de Janeiro. Assessor jurídico do Ministério Público do Estado do Rio de Janeiro. e-mail: nick.paliologo@ gmail.com.

* Doutor em Filosofia pelo IFCS UFRJ. Mestre em Direito pela Universidade de Coimbra. Coordenador adjunto do PPGD da UCP. e-mail: daniel.machado@ucp.br 


\section{INTRODUÇÃO}

A agenda do saneamento básico no Brasil ficou parada durante duas décadas, não havendo praticamente nenhum investimento significativo nos anos 80 e 90 , o que acarretou um enorme déficit em praticamente todas as cidades brasileiras. Com isso, observa-se um esforço cada vez maior em compreender a relevância do saneamento à garantia de uma vida digna, permitindo com que esse seja tomado como um direito humano e fundamental.

Em paralelo, a Constituição Federal foi conquistando força normativa e efetividade, ou seja, as normas constitucionais passaram a contar com aplicabilidade direta e imediata, não sendo somente uma mera convocação à atuação do legislativo e do executivo. Nesse sentido, os direitos constitucionais assumiram-se como direitos subjetivos em sentido pleno, comportando tutela judicial específica. O resultado desse processo é uma maior intervenção do Poder Judiciário nas atividades dos outros poderes, em especial o Poder Executivo. Assim, a intervenção judicial, mediante determinações à Administração Pública para a prestação de serviços de saneamento básico, procura concretizar os preceitos constitucionais e garantia dos direitos correlatos.

Nesse sentido, o objetivo do presente artigo é analisar se a falta de efetividade nas políticas públicas de saneamento básico no estado do Rio de Janeiro conduziu à uma judicialização excessiva desse direito e analisar os limites da atuação jurisdicional. Para isso, a metodologia adotada foi a revisão bibliográfica para compor a base teórica de conceitos referentes à doutrina brasileira da efetividade das normas constitucionais, o agigantamento do Poder Judiciário junto ao fenômeno da judicialização das políticas públicas e a construção do saneamento básico como um direito fundamental. Em seguida, adotou-se as análises quantitativas e qualitativas para abordar o panorama dos serviços de saneamento no estado do Rio de Janeiro e tratar das ações judiciais ajuizadas. Ao final, são analisados os parâmetros para a atuação do Poder Judiciário no controle jurisdicional das respectivas políticas públicas.

\section{Parte I - A doutrina da efetividade, papel do Poder Judiciário e a judicialização da política}

\section{I.I A doutrina da efetividade}

O constitucionalismo contemporâneo permitiu reconhecer a força normativa das normas constitucionais. Segundo Luís Roberto Barroso (2012, p. 05), essa conquista se deu no âmbito de um movimento jurídico-acadêmico conhecido como doutrina brasileira da efetividade. Tal 
movimento procurou não apenas elaborar as categorias dogmáticas da normatividade constitucional, como também superar algumas disfunções da formação nacional, que se materializavam na insinceridade normativa, no uso da Constituição Federal como uma mistificação ideológica e na falta de determinação política em dar-lhe cumprimento. Com isso, a essência da doutrina da efetividade é tornar as normas constitucionais aplicáveis direta e imediatamente, na extensão máxima de sua densidade normativa.

Daí as normas constitucionais, como as normas jurídicas em geral, são dotadas de imperatividade, a qual, por sua vez, pode ser descumprida por uma ação ou omissão. Uma vez ocorrida a violação, os sistemas constitucional e infraconstitucional devem prover meios para a tutela do direito ou bem jurídico afetados e restauração da ordem jurídica. Estes meios são a ação e jurisdição: ocorrendo uma lesão, o titular do direito ou alguém com legitimação ativa para protege-lo pode ir a juízo requerer reparação (BARROSO, 2012, p. 05).

De acordo com Barroso (2012, p. 06), a partir do momento que a Constituição Federal estabelece direitos subjetivos - políticos, individuais, sociais ou difusos - são eles, como regra, direta e imediatamente exigíveis, do Poder Público ou do particular, por via dos meios previstos no ordenamento. Assim, o Poder Judiciário passa a ter papel ativo e determinante na concretização da Constituição. A doutrina da efetividade se apoia em uma premissa positivista: direito constitucional é norma; e em um critério formal para estabelecer a exigibilidade de determinados direitos: se está na Constituição Federal é para ser cumprido. Contudo, a doutrina da efetividade deve conviver com novas formulações de base pós positivista que levam em conta fenômenos apreendidos mais recentemente, como a colisão entre normas - especialmente as que abrigam princípios e direitos fundamentais -, a necessidade da ponderação, bem como conceitos como mínimo existencial e o fundamento material dos direitos (BARROSO, 2012, p. 06). Nesse sentido, sempre que a Constituição Federal define um direito fundamental ele se torna exigível, inclusive por ação judicial.

Dessa forma, a doutrina brasileira da efetividade das normas constitucionais confere base teórica às demandas direcionadas ao Poder Judiciário, permitindo a judicialização de preceitos constitucionais.

\section{I.II O Poder Judiciário e a Judicialização}


É viável afirmar que a própria ideia de constitucionalismo e de previsão de questões políticas na Constituição Federal permitiriam que o Judiciário acabasse enfrentando qualquer questão política como sendo uma questão constitucional. Apesar de ser aparentemente contra os interesses do Parlamento, é possível afirmar que há um consenso acerca dos novos papeis que o Poder Judiciário vem assumindo, incluindo as decisões sobre questões políticas, morais, religiosas, centrais, tanto por parte da sociedade quanto por parte dos próprios atores políticos, os quais veem o Judiciário como um fórum apropriado para enfrentar essas questões (BARBOZA; KOZICKI, 2012, p. 61).

Esse agigantamento do Poder judiciário diante dos demais poderes é conhecido como judicialização da política. Esta foi a expressão formulada por C.N. Tate e T. Vallinder, em seu livro intitulado The Global Expansion of Judicial Power: The Judicialization of Politics (1995), para descrever os efeitos da expansão do Poder Judiciário no processo decisório das democracias contemporâneas.

O fenômeno da judicialização da política e das relações sociais tem sido motivo de controvérsias entre gestores da política, procuradores, juízes e intelectuais. O protagonismo dos juízes, bem como o ativismo do Poder Judiciário nas políticas públicas, parece inaugurar um novo capítulo na história do Poder Judiciário brasileiro. Mais afastados das decisões puramente técnicas e formais, passando a atuar como intérpretes da Constituição de 1988, os juízes vêm se tornando atores políticos com influência direta sobre o governo (SIERRA, 2014, p. 38).

Débora Maciel e Andrei Koerner (2002, p. 114) explicam que a judicialização da política requer que operadores da lei prefiram participar da policy-making a deixá-la ao critério de políticos e administradores e, em sua dinâmica, ela própria implicaria um papel político mais positivo da decisão judicial do que aquele envolvido em uma não decisão.

Nesse sentido é possível pensar na judicialização da política relacionada ao "novo estatuto dos direitos fundamentais e à superação do modelo de separação dos poderes do Estado, o que provoca uma ampliação dos poderes de intervenção dos tribunais na arena política" (VERBICARO, 2008, p. 391). Na tentativa de garantir à comunidade seus direitos elencados na Constituição Federal, a política acaba por se judicializar.

Isso ocorre, segundo Maria Sylvia Zanella Di Pietro (2017, p. 930), porque as políticas públicas são encaradas como instrumento adequado para concretizar os direitos fundamentais previstos constitucionalmente, especialmente na área social. Como o modelo do Estado Social 
é pródigo na proteção dos direitos fundamentais e na previsão de diversos serviços sociais como deveres do estado, a consequência inevitável é a de que acabam por se colocar em confronto, de um lado, o dever constitucional de atender às imposições constitucionais, que correspondem a direitos do cidadão (essenciais para garantir a dignidade da pessoa humana), e, de outro lado, a escassez dos recursos públicos para atender a todos esses direitos. Daí o princípio da reserva do possível: os deveres estatais, impostos pelo ordenamento jurídico, devem ser cumpridos na medida em que o permitam os recursos públicos disponíveis.

Loiane Prado Verbicaro (2008, p. 390) aponta algumas condições como facilitadoras do processo de judicialização da política, dentre as quais, destacam-se especialmente: (i) a promulgação da Constituição de 1988; (ii) a universalização do acesso à justiça; (iii) a existência de uma Constituição com textura aberta; (iv) a decodificação do direito, a crise do formalismo e do positivismo jurídico; (v) a ampliação do espaço reservado ao STF; (vi) a hipertrofia legislativa; e (vii) a crise do Parlamento brasileiro.

Além disso, é possível constatar-se que, no Brasil, a Justiça se aproximou da população por meio dos juizados especiais, nos quais o acesso independe de representação por advogado. Legislações especiais de proteção de minorias, como Código de Defesa do Consumidor, Estatuto da Criança e do Adolescente, Estatuto do Idoso, Lei Maria da Penha, levaram a um processo de substituição do Estado pelo Judiciário, tornando o juiz protagonista nas decisões sobre questões sociais, inclusive as que envolvem políticas públicas (VIANNA; BURGOS; SALLES, 2007, p. 41). Também é preciso compreender o fortalecimento de instituições como a Defensoria Pública e Ministério Público, as quais tornaram-se personagens relevantes na garantia de direitos.

Assim, a interferência do Poder Judiciário vai ganhando adeptos, sob alguns argumentos constitucionais: ao interferir em políticas públicas, o Judiciário não estaria invalidando matéria de competência dos outros Poderes do Estado, nem a discricionariedade que lhes é própria, porque está fazendo o seu papel de interpretar a Constituição. Ele está garantindo o núcleo essencial dos direitos fundamentais ou mínimo existencial indispensável para a dignidade da pessoa humana. Tratando-se de mínimo existencial, as normas constitucionais que o garantem não são meramente programáticas, mas, ao contrário, têm eficácia imediata, não dependendo de medidas legislativas ou administrativas para sua implementação. Em decorrência disso, a omissão do poder público, afrontando metas constitucionais, pode ser corrigida pelo Judiciário. 
Contudo, Di Pietro (2017, p. 934) afirma que é importante observar que, quando o Poder Judiciário analisa políticas públicas fixadas e implementadas pelos demais poderes, ele caminha em areias movediças. Todos os fundamentos em que se baseiam os defensores do controle judicial decorrem de conceitos jurídicos indeterminados, como dignidade da pessoa humana, núcleo essencial dos direitos fundamentais, mínimo existencial, razoabilidade, proporcionalidade. Não há critérios precisos que permitem definir o que é essencial para que se garanta a dignidade da pessoa humana, ou em que consiste o núcleo essencial dos direitos fundamentais ou mínimo existencial. E mesmo esse mínimo pode estar fora do alcance do Poder Público, pela limitação dos recursos financeiros. Não é por outra razão que o cumprimento das metas constitucionais exige planejamento. Também não é por outra razão que não se pode fugir inteiramente ao caráter programático das normas constitucionais.

\section{Parte II - Saneamento como direito básico e panoramas do saneamento básico no Estado do Rio de Janeiro.}

\section{II.I O Saneamento básico como direito}

Com o advento do Estado Socioambiental, a proteção ambiental passa a se projetar como um dos valores a ser incorporado como tarefa ou objetivo do Estado, reconhecendo-se a jusfundamentalidade do direito ao ambiente ecologicamente equilibrado, o que agregou novos elementos normativos ao conteúdo do mínimo existencial, fazendo com que se passasse a pensar um padrão mínimo em termos ambientais para a realização de uma vida digna e saudável, já que a qualidade e segurança ambiental são essenciais para o desenvolvimento da vida humana (SARLET; FENSTERSEIFER, 2017, p.140).

Nessa toada, Silva e Mandarino (2017, p. 33) entendem que os serviços de saneamento básico repercutem na promoção de mais de um direito fundamental: a saúde, a vida e o meio ambiente, de maneira que esses, mesmo que pertencentes a dimensões diversas, se conectam no momento de sua respectiva garantia. O que se quer dizer é que a garantia da saúde, por exemplo, naturalmente favorecerá a concretização do direito à vida e também da dignidade da pessoa humana, de maneira que é difícil garantir um direito fundamental isoladamente em virtude da forte interdependência entre eles. 
Em âmbito internacional, através da Resolução nº 64/292 (A/RES/64/292), de 2010, a Assembleia Geral das Nações Unidas reconheceu a água limpa e segura e o saneamento como um direito humano essencial ao gozo pleno da vida, bem como de todos os demais direitos de mesma natureza. Seguindo esse posicionamento, o Conselho de Direitos Humanos adotou o entendimento, por meio da Resolução no $16 / 5$, do acesso à água potável e ao saneamento como sendo um direito humano conectado aos direitos à vida e à dignidade (SILVA; MANDARINO, 2017, p. 26).

Já em 2015, a ONU, com a Resolução nº 70/169 (A/RES/70/169), aprimorou a resolução de 2010 e passou a entender o direito à água e ao saneamento como direitos distintos e autônomos. Até então o direito humano à água e o direito humano ao saneamento básico eram tratados como se fossem únicos. Contudo, o novo entendimento reconheceu dois direitos conectados, mas distintos, ambos integrantes do direito à vida (STRAKOS, 2016, p.146).

Para abordar o direito ao saneamento básico no ordenamento nacional, é preciso compreender que os direitos sociais, categoria em que se encontra o direito ora em análise, podem ser classificados em originários ou derivados. A primeira categoria está relacionada àqueles que advêm do texto constitucional ou mesmo de um tratado de direitos humanos sem outra implementação legislativa ou administrativa. Já o direito social derivado é aquele que já possui regulamentação legal ou administrativa e que pode ser encarado pelo prisma da igualdade, assegurando o acesso igualitário a todos e ainda pelo prisma da segurança e confiança no Estado, impedindo que haja inconstância na prestação e proibindo-se o retrocesso (RAMOS, 2016, p. 67).

Ainda vale lembrar que a enumeração constitucional dos direitos não é exaustiva, uma vez que o artigo $5^{\circ}, \S 2^{\circ}$ prevê o princípio da não exaustividade dos direitos fundamentais, também denominado abertura da Constituição aos direitos humanos, dispondo que os direitos previstos não excluem outros decorrentes do regime e princípios da Constituição, além dos que estão mencionados no restante do texto constitucional e em tratados de direitos humanos celebrados pelo Brasil (RAMOS, 2016, p. 65).

Estes pressupostos constitucionais são relevantes, uma vez que o direito ao saneamento básico não está explícito na Constituição Federal de 1988. Entretanto, Chagas Pinto (2006, p. 406) afirma ser possível o reconhecimento de um direito fundamental ao saneamento básico, através de uma interpretação extensiva do direito fundamental à saúde, e, principalmente, do 
direito fundamental ao meio ambiente ecologicamente equilibrado (art. 225 da Constituição Federal de 1988).

O saneamento básico opera como um instrumento de combate da pobreza e da degradação do ambiente, de modo que a efetividade dos seus serviços (abastecimento de água, esgotamento sanitário, limpeza urbana e manejo de resíduos sólidos e drenagem e manejo de águas pluviais urbanas), integra, direta ou indiretamente, o âmbito normativo de diversos direitos fundamentais, como o direito à saúde, o direito à habitação decente, o direito ao ambiente e, até mesmo, o direito à vida (PINTO, 2006, p. 408).

Tal entendimento está refletido na Lei Federal de Saneamento Básico, quando enuncia, entre os princípios fundamentais da política de saneamento, a articulação com as políticas de desenvolvimento urbano e regional, de habitação, de combate à pobreza e sua erradicação, de proteção ambiental, de promoção da saúde e outras de relevante interesse social voltadas para a melhoria da qualidade de vida, para as quais o saneamento seja fator determinante (art. $2^{\circ}$, IV), o que acaba por relevar uma visão integrada para a tutela e promoção de direitos (SARLET; FENSTERSEIFER, 2017, p.149).

Vale ressaltar, ainda, a Proposta de Emenda Constitucional (PEC) n ${ }^{\circ}$ 6/2016 que tem a intenção de modificar o artigo $6^{\circ}$ da Constituição Federal a fim de integrar expressamente o saneamento básico como direito social.

\section{II.II Breve panorama do saneamento básico no estado do Rio de Janeiro}

Como foi visto acima o saneamento básico é um direito assegurado pela Constituição Federal e definido pela Lei $\mathrm{n}^{\circ} 11.445 / 2007$ como o conjunto de serviços, infraestrutura e instalações operacionais de abastecimento de água, esgotamento sanitário, limpeza urbana, drenagem urbana, manejos de resíduos sólidos e de águas pluviais. Nesse momento, o artigo analisa a prestação de cada um dos serviços no Estado do Rio de Janeiro a fim de medir sua efetividade ${ }^{1}$.

\footnotetext{
${ }^{1}$ O presente artigo optou por utilizar bases de dados de caráter nacional, como a Agência Nacional de Águas, Sistema Nacional de Informações sobre Saneamento, Abrelpe e Instituto Trata Brasil, por isso que os serviços de drenagem urbana e manejo de águas pluviais não são abordados, uma vez que o relatório da Agência Nacional de Águas está em fase de elaboração pela primeira vez.
} 
Com base nos dados divulgados pelo Sistema Nacional de Informações sobre Saneamento (SNIS), o Instituto Trata Brasil ${ }^{2}$ elaborou o relatório Benefícios Econômicos e Sociais da Expansão do Saneamento no Rio de Janeiro. Segundo esse relatório, em 2005, 83,3\% da população carioca foi contemplada com abastecimento de água em suas residências. Em 2015, essa proporção subiu para 92,1\% da população, ou seja, 2,65 milhões de habitantes passaram a ter acesso a esse serviço básico. No caso da coleta de esgoto, a cobertura chegou a apenas $64,5 \%$ dos habitantes em 2015, indicando um aumento de 9 pontos da população em dez anos. Nesse período, 3,87 milhões de pessoas passaram a ter acesso ao serviço de coleta de esgoto (INSTITUTO TRATA BRASIL, 2017, p. 07).

GRÁFICO 1 - População atendida por serviços de água e esgoto, Estado do Rio de Janeiro, (\%) da população total.

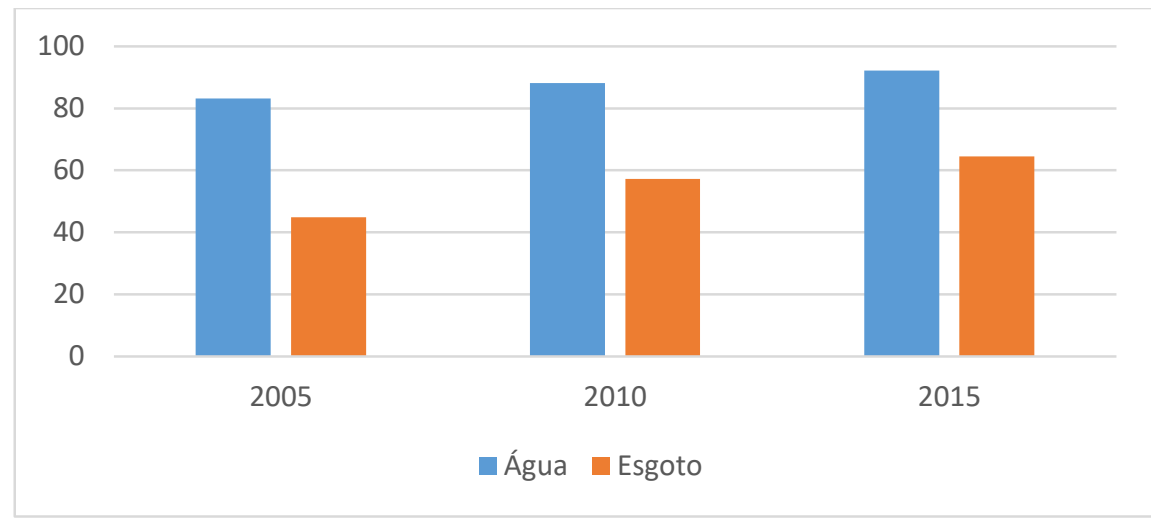

Fonte: Instituto Trata Brasil, 2017.

Contudo, o maior problema do saneamento básico no Brasil continua sendo a falta de tratamento do esgoto. Além do déficit de serviços de coleta, há uma parcela grande do esgoto coletado que não é tratado. Em 2015, do esgoto coletado nas residências brasileiras recebia tratamento antes de retornar ao meio ambiente apenas $73,4 \%$. Os demais $26,6 \%$ do esgoto coletado não recebiam qualquer tipo de tratamento. Assim, a coleta realizada nesses locais constituía um sistema de simples afastamento do esgoto das residências (INSTITUTO TRATA BRASIL, 2017, p. 10).

\footnotetext{
${ }^{2}$ Organização da Sociedade Civil de Interesse Público formada por empresas com interesse nos avanços do saneamento básico e na proteção dos recursos do país. 
No estudo divulgado pela Agência Nacional de Águas (2017), Atlas Esgotos: Despoluição de Bacias Hidrográficas, foi elaborado um abrangente trabalho de diagnóstico da situação atual quanto ao esgotamento sanitário de todas as sedes municipais do país. Quanto aos 92 municípios que integram o Estado do Rio de Janeiro, é possível perceber que somente $42,25 \%$ da população recebe o devido atendimento, tendo seu esgoto coletado e tratado. Como pode se verificar pelo gráfico a seguir:

GRÁFICO 2 - População atendida por serviços de esgotamento, Estado do Rio de Janeiro, (\%) da população total.

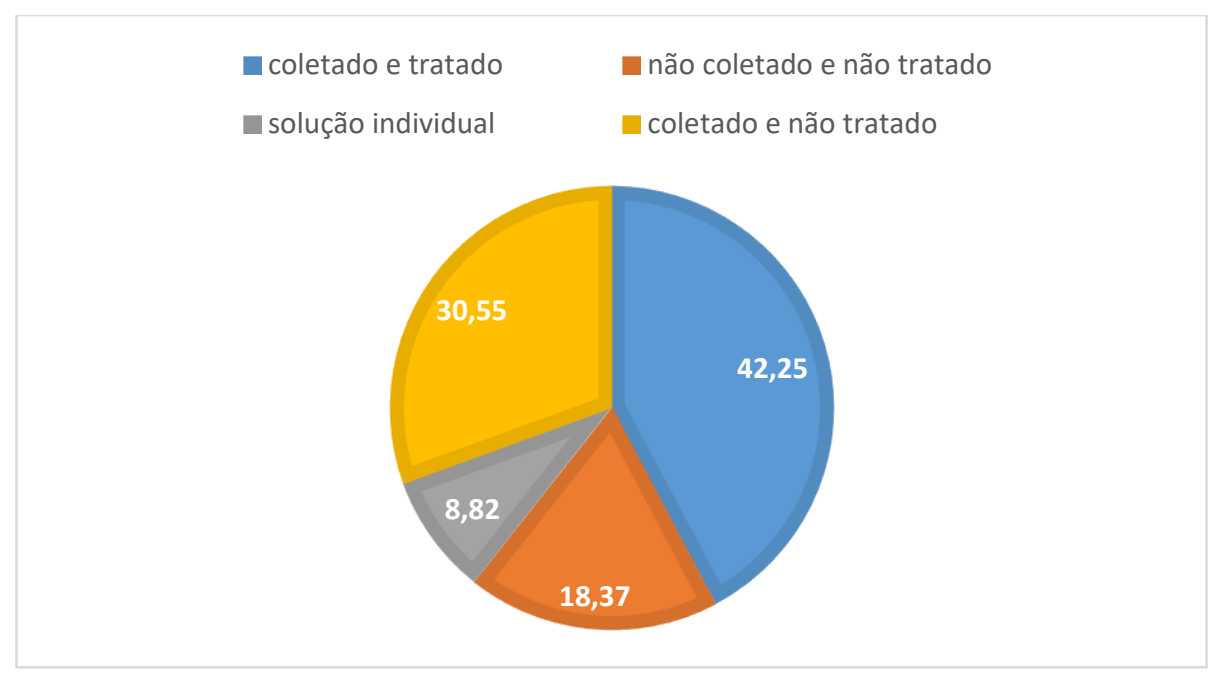

Fonte: Agência Nacional de Águas, 2017.

Além de todos os índices trabalhados anteriormente, o estado do Rio de Janeiro conta com dois municípios (Duque de Caxias e Nova Iguaçu, posições $91^{\circ}$ e $92^{\circ}$, respectivamente) entre os piores do país, segundo o ranking de saneamento das cem maiores cidades brasileiras no ano de $2017^{3}$, elaborado pelo Instituto Trata Brasil a partir de dados do Sistema Nacional de Informações sobre Saneamento (SNIS), levando em consideração a evolução dos indicadores

\footnotetext{
${ }^{3}$ Em 2018, foi divulgado um novo ranking, porém optou-se por utilizar o do ano de 2017 a fim de manter a coerência com os demais dados. 
de água, esgotos, investimentos e perdas de águas (INSTITUTO TRATA BRASIL, 2017, p. 90).

No que toca aos serviços de manejo de resíduos sólidos e limpeza urbana, a Associação Brasileira de Empresas de Limpeza Pública e Resíduos Especiais (Abrelpe), em seu relatório Panorama dos Resíduos Sólidos no Brasil 20154, destaca que a produção diária do estado carioca era de 22.213 toneladas por dia, sendo coletados somente 21.895 toneladas (ABRELPE, 2015 , p. 56).

Do total de resíduos sólidos produzidos no estado do Rio de Janeiro, 10\% (2.188 toneladas) eram direcionados aos lixões, $68,6 \%$ aos aterros sanitários e 21,4\% aos chamados aterros controlados, os quais não possuem o conjunto de sistemas e medidas necessários para proteção do meio ambiente contra danos e degradações (ABRELPE, 2015, p. 56).

GRÁFICO 3 - Disposição final de resíduos sólidos no estado do Rio de Janeiro (\%)

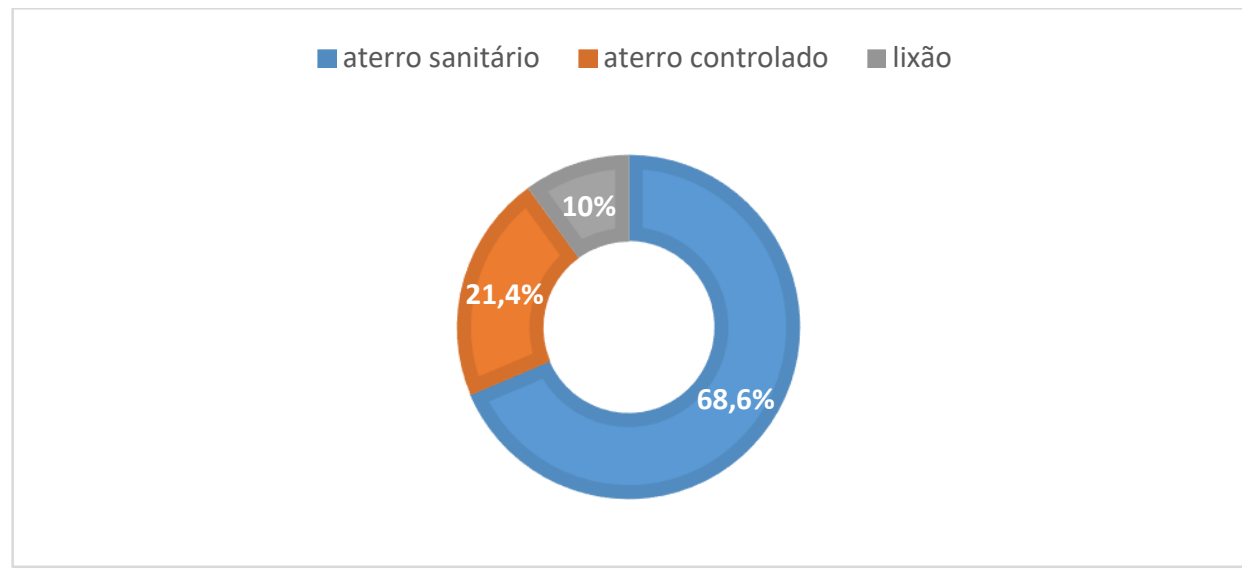

Fonte: Associação Brasileira de Empresas de Limpeza Pública e Resíduos Especiais, 2015.

Em relação aos investimentos realizados no setor, entre 2005 e 2015, as empresas brasileiras e os governos estaduais e municipais desembolsaram $\mathrm{R}$ 9,264 bilhões por ano, em média, para a realização de obras de manutenção e expansão das redes de água e esgoto. No caso do Estado do Rio de Janeiro, as empresas de saneamento e os governos estaduais e municipais investiram $\mathrm{R}$ \$ 530,11 milhões por ano, em média, para realização de obras de

\footnotetext{
${ }^{4}$ Apesar da divulgação do estudo 2016, a opção pelo relatório de 2015 foi para manter coerência com os outros estudos utilizados no presente artigo. 
manutenção e expansão das redes de água e esgoto (INSTITUTO TRATA BRASIL, 2017, p. 12).

Em termos gerais, o Estado do Rio de Janeiro apresenta bons índices de saneamento básico em relação ao resto do Brasil. Contudo, há uma parcela da população que continua não sendo alcançada pelas políticas públicas de expansão desses serviços, como é o caso do esgotamento sanitário. Esse serviço, em particular, apresenta um déficit elevado em relação aos outros, uma vez que é composto de várias etapas, as quais vão da coleta ao tratamento. Muitas vezes, o que se vê é a prestação somente da coleta sem tratamento.

\section{Parte III - A judicialização do saneamento básico no Estado do Rio de Janeiro}

O Poder Judiciário acabou por se consolidar como um dos principais instrumentos para os cidadãos acessarem os serviços públicos e privados, o que acaba levando a uma judicialização excessiva de algumas áreas como a saúde, por exemplo. Outras áreas estão passando pelo mesmo processo, como é o caso do saneamento básico. A Associação das Empresas de Saneamento Básico Estaduais (Aesbe), que representa as 25 maiores prestadoras do serviço no Brasil, manifestou preocupação com a crescente judicialização do setor ao participar do Seminário Diálogos Estratégicos: Desafios e Perspectivas para o Saneamento Básico, promovido pelo Instituto Brasiliense de Direito Público em 2016.

Para a Aesbe, órgãos como o Ministérios Público, Tribunais de Conta e até os Juízos de primeira instância precisam entender que as operadoras são somente um componente da política de saneamento. A condenação por deficiências resultantes do déficit histórico no setor não é razoável e, em vez de contribuir para a melhoria do saneamento, faz retroceder, pela insegurança jurídica que provoca. Um caso emblemático é a Companhia de Saneamento Básico do Estado de São Paulo (Sabesp), que de acordo com o presidente, Jerson Kelman, há R \$40 bilhões em passivo de judicialização, sendo que a empresa está avaliada em R \$20 bilhões (MAIA, 2016).

No estado fluminense, a Companhia Estadual de Águas e Esgoto do Rio de Janeiro (CEDAE), cuja área de atuação abrange 64 dos 92 municípios do estado, figura entre os 30 
maiores litigantes do estado, segundo lista divulgada pelo Tribunal de Justiça estadual (2017). Entre o período de 2013 e 2017, a empresa ocupou a $8^{\mathrm{a}}$ e $16^{\mathrm{a}}$ posição a partir da contagem dos processos ajuizados com origem nas varas cíveis e juizados especiais respectivamente. Em cinco anos, foram 54.524 processos no total ${ }^{5}$.

Em relação ao número de processos referidos no parágrafo anterior, grande parte diz respeito à polêmica acerca da taxa de esgoto cobrada pela Cedae. O Superior Tribunal de Justiça entende que é cabível a respectiva taxa mesmo que não haja um tratamento final adequado aos resíduos. Já o Tribunal de Justiça do Rio de Janeiro entende que deve existir um tratamento final aos dejetos, ou seja, não basta haver somente a coleta, caso contrário a taxa não pode ser cobrada em sua integralidade. Segundo o Tribunal estadual, esse entendimento se justifica no artigo 225 da Constituição Federal que prevê o direito ao meio ambiente ecologicamente equilibrado.

Considerando o Ministério Público como um ator fundamental na dinâmica da judicialização, requereu-se informações junto ao órgão acerca do ajuizamento de ações civis públicas inseridas nas demandas de saneamento básico. Com as informações em mãos foi observado o ajuizamento de 144 ações, entre o período entre 2013 e novembro de $2017^{6}$. Os pedidos são os mais variados: elaboração pelo poder público do Plano Municipal de Resíduos Sólidos; implantação de unidade de tratamento de lixo; obras para o fornecimento dos serviços de abastecimento de água e coleta de esgoto; medidas que evitem enchentes; entre outros. Essas ações se distribuem da seguinte maneira de acordo com os serviços que fazem parte do saneamento básico em geral:

GRÁFICO 4 - DISTRIBUIÇÃO DAS AÇÕES AJUIZADAS PELO MINISTÉRIO PÚBLICO DE ACORDO COM O SERVIÇOS COMPONENTES DO SANEMANETO BÁSICO NO PERÍODO DE 2013 À NOVEMBRO DE $2017(\%)$.

\footnotetext{
${ }^{5}$ O período de 2013 a 2017 é o intervalo das informações apresentadas pelo Tribunal de Justiça do Estado do Rio de Janeiro. Vale ressaltar que parte dos 54.524 processos versam sobre matéria consumerista, nas quais são discutidas pagamento de taxas, por exemplo.

${ }^{6}$ Foi requerido ao Ministério Público informações das ações ajuizadas sobre saneamento básico a partir de 2007, marco regulatório para o setor, até 2018. Contudo, as informações prestadas foram a partir de 2013. 


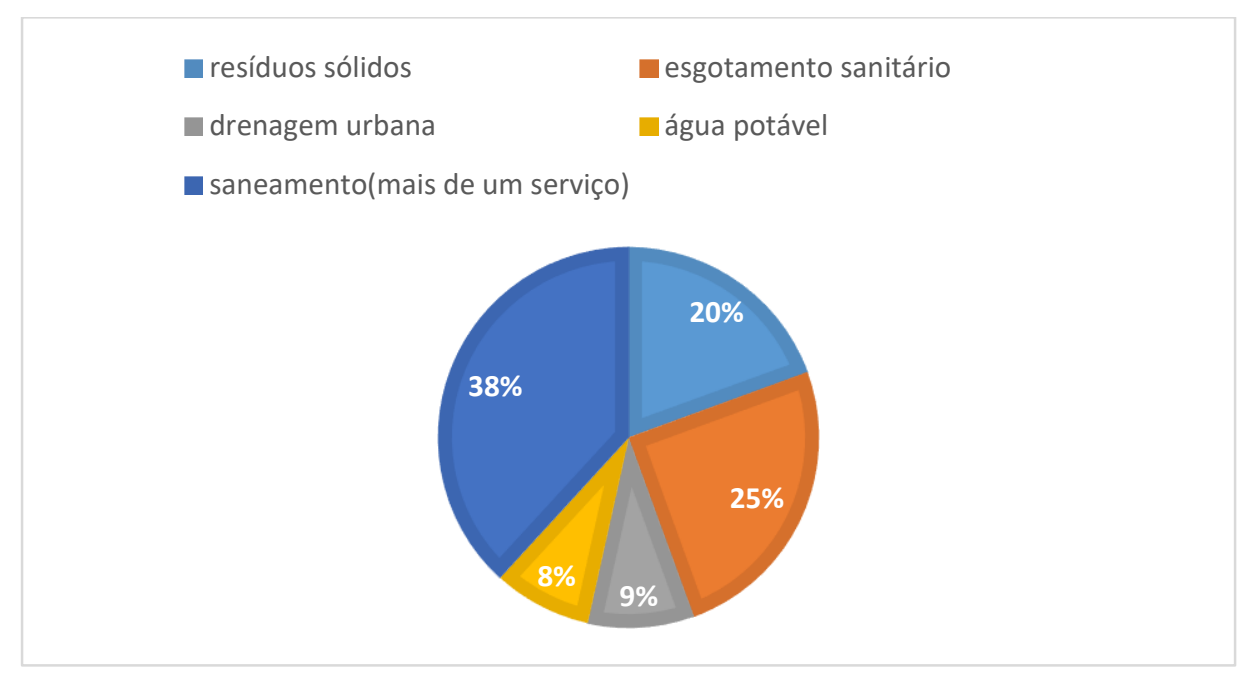

Fonte: Informações recebidas do Ministério Público do Estado do Rio de Janeiro através da Lei de Acesso à Informação, 2017.

É possível perceber que as ações que versam sobre mais de um serviço apresentam o maior índice (38\%). Apesar disso, o serviço mais judicializado individualmente foi o esgotamento sanitário (25\%), que é justamente o serviço com grau mais elevado de deficiência, como foi abordado no item anterior.

Os casos de dois municípios se destacam em relação aos demais: São Gonçalo e Nova Friburgo. Em relação ao primeiro, foram ajuizadas pelo Ministério Público 22 ações civis públicas requerendo os serviços de fornecimento de água, captação e tratamento de esgoto para 22 duas localidades diferentes. Em todos os casos, a Cedae alegou que as obras necessárias já estavam sendo elaboradas de acordo com o plano municipal de saneamento básico. $^{7}$

Nesse ponto, é fundamental compreender o instrumento de planejamento municipal de políticas públicas no setor do saneamento, qual seja o plano municipal de saneamento básico. A lei $n^{\circ} 11.445 / 07$ determina que toda prestação de serviços de saneamento deverá observar um plano, o qual será aprovado por ato dos titulares (art. 19, $\S 1^{\circ}$ ), quais sejam os municípios. O decreto 7.217/10 regulamenta o planejamento como sendo as atividades atinentes à identificação, qualificação, quantificação, organização e orientação de todas as ações, públicas e privadas, por meio das quais o serviço público deve ser prestado ou colocado à disposição de

${ }^{7}$ Os processos ainda se encontram em trâmite, sem uma decisão final. Foi determinado pelo juízo, mediante a alegação da Cedae, que houvesse verificação da existência e andamento das obras.

${ }^{8}$ Dados recebidos pelo Ministério Público do estado do Rio de Janeiro através da Lei de Acesso à Informação. 
forma adequada. O plano pode ser específico para cada serviço (art. 19, caput), como, por exemplo, a elaboração de um plano para abastecimento de água e outro para esgotamento sanitário, ou abranger mais de um serviço, sendo o titular dos serviços o responsável pela consolidação e compatibilização dos vários planos específicos para cada serviço (art.19 § $2^{\circ}$ ). Outra exigência é a compatibilidade com o plano plurianual, inclusive a lei exige que os planos de saneamento sejam revistos periodicamente, em prazo não superior a quatro anos, anteriormente à elaboração do plano plurianual (art. 19, § $\left.4^{\circ}\right)$.

Em uma ação civil pública ajuizada pelo Ministério Público em face do município de Nova Friburgo e da empresa responsável pelo saneamento - Águas de Nova Friburgo - foi requerida a antecipação das obras de coleta e tratamento de esgoto em um determinado bairro que já estava nos planos de expansão dos serviços. Como tutela provisória, o Ministério Público requereu que o Poder Público selecionasse a proposta mais vantajosa para realização dos serviços e desse início as obras no prazo de 60 dias, sob pena de multa diária de $\mathrm{R} \$ 10.000,00$, a qual foi deferida pelo juízo de primeira instância. Esse é um exemplo do descompasso entre a atuação do Poder Judiciário e a atuação da Administração Pública. ${ }^{9}$

É possível perceber que a atuação do Poder Judiciário, muitas vezes, vai de encontro ao planejamento da Administração Pública municipal para a expansão dos serviços ou coloca decisões impossíveis de serem cumpridas, atrapalhando a consolidação e expansão dos próprios serviços de saneamento. É claro que diante da violação de um direito fundamental é legítimo recorrer ao judiciário para que tal situação seja reparada, contudo o Poder Judiciário deve olhar com atenção o planejamento das políticas públicas já encabeçado pelo poder público responsável. Com esse direcionamento, é necessário refletir sobre alguns parâmetros de atuação ao tratar de políticas de saneamento, sendo este o ponto tratado adiante.

\section{Parte IV - Limites e parâmetros ao controle judicial da política de saneamento}

O Poder Judiciário deve seguir alguns parâmetros ao controlar políticas públicas, segundo Vanice Regina Lírio do Valle (2016, p. 167), firmada a premissa do imperativo constitucional do agir da Administração, articulado através de uma política pública formal e expressamente enunciada, têm-se como consequência, num quadro de funcionamento normal

${ }^{9} \mathrm{O}$ número da ação é 0008385-25.2017.8.19.0037. O deferimento da tutela provisória foi revertido em recurso. 
do poder, que o controle jurisdicional há de ter por objeto inicial de cogitação a investigação no tema contido na demanda, quanto à existência de uma política pública, a qual se poria como questão prejudicial lógica à outorga da prestação jurisdicional. Esse seria o caso de omissão do poder público.

Vanice Lírio (2016, p. 167) entende políticas públicas como um conjunto de processos voltados a formular e a executar ações que implementam a realização efetiva e concreta dos cometimentos constitucionalmente atribuídos, explícita ou implicitamente, obrigatória ou dispositivamente, ao sistema decisório juspolítico governança-administração.

Afinal, se o agir da Administração se há de inserir sempre em um horizonte de programação que se expressa através de políticas públicas, a existência em si desse mesmo instrumento constitui a indagação primária, que distinguirá, inclusive, uma conclusão no sentido de omissão absoluta, daquela de insuficiência ou de inadequação do planejamento formalmente posto ao agir estatal. Dessa investigação primária, o objeto da medida jurisdicional pode ser determinado: obrigação de formular-se a política pública ou produto dessa, individualmente considerado. Isto é, uma resposta ao descumprimento do dever constitucional da Administração e, não só, de garantia de um determinado direito fundamental em favor deste ou daquele jurisdicionado (VALE, 2016, pp. 167 - 168).

Contudo, nem só da ausência absoluta de política pública poderá vir a se ocupar o Poder Judiciário. É possível que a hipótese submetida à apreciação jurisdicional tenha sido objeto, concretamente, de uma política pública formalmente enunciada. Nesses casos, a política pública já foi definida pela própria Administração Pública, logo restará vinculativa. O Poder Judiciário atuaria a fim de coagir o poder público a agir conforme os próprios compromissos que traçou (VALE, 2016, pp. $168-169$ ).

Quando se fala de políticas públicas de saneamento básico, a Lei Federal 11.445/07, marco regulatório do setor, traz outros elementos a serem observados pelo Poder Judiciário, quando em sede de controle jurisdicional, e pela própria Administração pública.

A norma federal traz princípios fundamentais para a Política Nacional de Saneamento Básico, como a universalização do acesso aos serviços em seu o artigo $2^{\circ}$, inciso III a "ampliação progressiva do acesso de todos os domicílios ocupados ao saneamento básico". Contudo, a universalização do acesso importa em custos. Dessa forma, não seria possível concretizá-la de forma imediata ou a curto prazo, ainda que houvesse ordem judicial nesse 
sentido. Assim, o Poder Público deve adotar medidas de planejamento e de alocação adequada de recursos a fim de tornar viável a ampliação progressiva até à universalização (MORAIS, 2007, p. 122).

A lei é bem enfática na obrigatoriedade de planejamento e fixação de metas. Exige expressamente que cada titular do serviço elabore seu plano de saneamento básico (art. 19), contendo pelo menos: a) o diagnóstico da situação; b) os objetivos e metas de curto, médio e longo prazos para a universalização dos serviços, admitidas soluções graduais e progressivas; c) os programas, projetos e ações necessárias para atingir os objetivos e as metas fixadas, de modo compatível com os respectivos planos plurianuais e com outros planos governamentais relacionados, identificando possíveis fontes de financiamento; d) ações a serem adotas em situações emergenciais; e e) mecanismos e procedimentos para a avaliação sistemática da eficiência (artigo 19) (MORAIS, 2007, p. 123).

Isso significa que o administrador público não pode simplesmente se apoiar no argumento de não possuir orçamento necessário à expansão dos serviços. Tem de examinar a situação concreta, fixar planos e metas e buscar fontes de financiamento para viabilizar as ações necessárias. Por isso a lei estabelece a compatibilidade entre o plano de saneamento básico e o plano plurianual, o que deve ser observado também em sede de controle jurisdicional (MORAIS, 2007, pp. 123 - 124).

Segundo Marília de Oliveira Morais, a necessidade de compatibilidade com o plano plurianual deve ser adequadamente compreendida dentre as diretrizes fixadas pela lei $\mathrm{n}^{\mathrm{o}}$ 11.445/2007 para a elaboração dos planos de saneamento básico de cada titular, determina-se que estes serão "revistos periodicamente, em prazo não superior a 4 (quatro) anos, anteriormente à elaboração do Plano Plurianual" (art.19, $4^{\circ}$ ). No mesmo sentido, o plano nacional de saneamento básico e os planos regionais de saneamento básico, que são elaborados com horizonte de 20 (vinte) anos, devem ser "avaliados anualmente e revisados a cada 4 (quatro) anos, preferencialmente em períodos coincidentes com os de vigência dos planos plurianuais" (art.52, $\S 2^{\circ}$ ) (MORAIS, 2007, p. 124).

Ao atuar, o Poder Judiciário não pode simplesmente dar provimento jurisdicional sem observar os impactos orçamentários e atuação prévia do Poder Público, como planos de metas, por exemplo. 


\section{CONSIDERAÇÕES FINAIS}

Como foi visto no presente artigo, a doutrina da efetividade tem por essência tornar as normas constitucionais aplicáveis direta e imediatamente, na extensão máxima de sua densidade normativa, permitindo que uma vez violadas sejam objeto de demanda judicial. Isso faz com que o Poder Judiciário assuma um papel predominante na consolidação dos ditames constitucionais, ainda mais diante do déficit de atuação do poder público. Nesse sentido, o saneamento básico, constantemente violado e como direito fundamental a ser garantido, tornase objeto recorrente de ações judiciais.

O controle judicial sobre essas políticas públicas influencia diretamente a atuação da Administração Pública, a partir do momento em que ordens judicias determinam a expansão desses serviços ou a construção de unidades de tratamento de esgoto, por exemplo. Tudo isso sem atentar-se ao planejamento existente. O setor de saneamento básico conta ainda com um agravante que é a complexidade e custo elevado das obras.

Foi visto que no estado do Rio de Janeiro os serviços de saneamento apresentam índices considerados elevados quando comparados com a média nacional, mas o serviço de esgotamento sanitário alcança menos da metade da população, sendo o serviço mais deficitário no estado. Ao verificar as ações judiciais que versam sobre o assunto, percebeu-se que, em cinco anos, a principal empresa prestadora do serviço figurou em mais de 50 mil processos. $\mathrm{O}$ Ministério Público, importante ator na dinâmica da judicialização, foi responsável pelo ajuizamento de 144 ações civis públicas, sendo 22 ações civis públicas somente no município de São Gonçalo.

Em relação a atuação do Poder Judiciário, verificou-se que as decisões desrespeitam por completo o planejamento público para o setor, burlando previsões orçamentárias e os planos municipais. Por vezes, as decisões emitidas não são nem possíveis de serem atendidas. É claro que diante da violação de um direito fundamental é legítimo recorrer ao judiciário para que tal situação seja reparada, contudo o Poder Judiciário deve olhar com atenção o planejamento das políticas públicas já encabeçado pelo poder público responsável. Com esse direcionamento, é necessário refletir sobre alguns parâmetros de atuação ao tratar de políticas de saneamento, como a compatibilidade do plano municipal com as leis orçamentárias, conforme a própria lei 11.445/07 aponta. 


\section{REFERÊNCIAS}

AGÊNCIA NACIONAL DE ÁGUAS. Atlas esgotos: despoluição de bacias hidrográficas. Brasília: ANA, 2017.

ASSOCIAÇÃO BRASILEIRA DE EMPRESAS DE LIMPEZA URBANA E RESÍDUOS ESPECIAIS. Panorama dos Resíduos Sólidos no Brasil 2015. São Paulo.2015. Disponível em: < http://www.abrelpe.org.br/Panorama/panorama2015.pdf $>$ Acesso em: 17/12/2017

BARBOZA, Estefênia Maria de Queiroz; KOZICKI, Katya. Judicialização da Política e Controle Judicial de Políticas Públicas. Rev. Direito GV vol.8 no.1 São Paulo Jan./June. 2012.

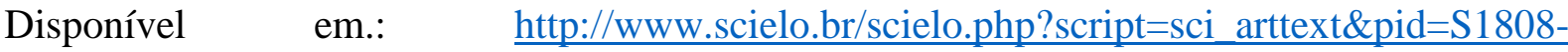
24322012000100003. Acesso em.: 11/12/2017

BARROSO, Luís Roberto. Da falta de efetividade à judicialização excessiva: direito à saúde, fornecimento de medicamentos e parâmetros para a atuação judicial. In Judicialização, ativismo judicial e legimidade democrática. [Syn]Thesis, Rio de Janeiro, vol.5, $\mathrm{n}^{\circ} 1,2012$. Acesso em 11/12/2017. Disponível em.: <http://pfdc.pgr.mpf.mp.brlatuacao-e-conteudos-deapoio/publicacoes/saude/Saude__judicializacao___Luis_Roberto_Barroso.pdf.> Acesso em $11 / 12 / 2017$

CARVALHO, Ernani. Em busca da judicialização da política no brasil: apontamentos para uma nova abordagem. Revista de Sociologia e Política, n.23. Curitiba, UFPR, 2004, pp 115126.

DI PIETRO, Maria Sylvia Zanella. Direito Administrativo.30.ed. Rio de Janeiro: Forense,2017. INSTITUTO TRATA BRASIL. Benefícios econômicos e sociais da expansão do saneamento no Rio de Janeiro. São Paulo, março de 2017.

Ranking do Saneamento 2017. São Paulo. 2017. Disponível em: < http://www.tratabrasil.org.br/datafiles/estudos/ranking/2017/relatorio-completo.pdf $>$ Acesso em: $17 / 12 / 2017$

MACIEL, Débora Alves; KOERNER, Andrei. Sentidos da Judicialização da Política: duas análises. Lua Nova, n. 57. São Paulo, Cedec 2002. pp 113-133. 
MAIA, Flavia. População precisa recorrer à Justiça para conseguir o direito básico ao saneamento.

Disponível em:

http://www.correiobraziliense.com.br/app/noticia/especiais/dialogos-

estrategicos/2016/09/27/noticia-dialogos-estrategicos-correio-braziliense,550561/populacaoprecisa-recorrer-a-justica-para-conseguir-o-direito-basico-a.shtml >. Acesso em: 19/12/2017

MORAIS, Marília de Oliveira. Saneamento Básico: funções e limites do controle judicial. Dissertação de mestrado - Centro de Ciências jurídicas/ Faculdade de Direito do Recife. Universidade Federal de Pernambuco. Recife,2007.

PINTO, Bibiana Graeff Chagas. Saneamento básico e direitos fundamentais:questões referentes aos serviços públicos de água e esgotamento sanitário no direito brasileiro e no direito francês. In: CONGRESSO INTERNACIONAL DE DIREITO AMBIENTAL (DIREITOS HUMANOS E MEIO AMBIENTE)., 10., 2006, São Paulo. Anais [...]. São Paulo: Imprensa Oficial do Estado de São Paulo, 2006. p. $385-441$. Disponível em:< http://www.planetaverde.org/biblioteca-virtual/anais/anais-do-10\%C2\%BA-congressointernacional-de-direito-ambiental-direitos-humanos-e-meio-ambiente-v-2>. Acesso em: 8 dez. 2018.

RAMOS, André de Carvalho. Curso de Direitos Humanos. 3. Ed. rev., atual. e ampl. São Paulo: Saraiva, 2016.

SARLET, Ingo Wolfgang; FENSTERSEIFER, Tiago. Direito Constitucional Ambiental. 5. Ed. rev., atual. e ampl. São Paulo: Editora Revista dos Tribunais, 2017.

SIERRA, Vânia Morales. O Poder Judiciário e o Serviço Social na judicialização da política e da questão social. SER Social, Brasilia, v.16,n.34,jan/jul 2014. Disponível em.: < http://periodicos.unb.br/index.php/SER_Social/article/viewFile/11707/8229> Acesso em.: $11 / 12 / 2017$

SILVA, Cintia da; MANDARINO, Luca Moura. O Saneamento Básico e a Dogmática dos Direitos Fundamentais. In: SADDY, André; CHAUVET, Rodrigo da Fonseca (coord.). Aspectos Jurídicos do Saneamento Básico. Rio de Janeiro: Lumen Juris, 2017. p. 25 -48 .

STRAKOS, Paula. Água como direito humano: Estudo comparado de sua proteção nas esferas judiciais interamericana e europeia. Revista da Faculdade de Direito - UFPR, Curitiba, ano 
2016, v. 61, n. 3, p. $141 \quad-164$, 2016. Disponível em: https://revistas.ufpr.br/direito/article/view/46092. Acesso em: 11 jan. 2019.

TRIBUNAL DE JUSTIÇA DO ESTADO DO RIO DE JANEIRO. Página Institucional. Disponível em: < http://www.tjrj.jus.br/> . Acesso em 19/12/2017

VALLE, Vanice Regina Lírio do. Política públicas, direitos fundamentais e controle judicial.2.ed. Belo Horizonte. Fórum,2016.

VALLINDER, T. \& TATE, C. Neal. The Global Expansion of Judicial Power : The Judicialization of Politics. New York : New York University.1995

VERBICARO, Loiane Prado. Um estudo sobre as condições facilitadoras da judicialização da política no Brasil. Revista Direito FGV, n. 4, 2008.

VIANNA, Luiz Werneck; BURGOS, Marcelo Baumann; SALLES, Paula Martins. Dezessete anos de judicialização da política. Tempo Soc., São Paulo, v. 19, n. 2, nov. 2007. 